\title{
STRUCTURE OF A NEW ISOFLAVONE FROM FUNGI AND STREPTOMYCES INHIBITING DOPA DECARBOXYLASE
}

\author{
Hiroyasu Tobe, Hiroshi Naganawa, Tomohisa Takita, \\ Tomio Takeuchi and Hamao Umezawa \\ Institute of Microbial Chemistry, Kamiosaki, Shinagawa-ku, Tokyo, Japan
}

(Received for publication March 1, 1976)

\begin{abstract}
A new dopa decarboxylase inhibiting isoflavone has been isolated from culture filtrates of fungi and streptomyces and shown to be $3^{\prime}, 4^{\prime}, 5,7$-tetrahydroxy-8-methoxyisoflavone.
\end{abstract}

As reported in a previous paper, ${ }^{1)}$ five isoflavone compounds inhibiting dopa decarboxylase were isolated from culture filtrates of Aspergillus niger NRRL-3122 and Streptomyces neyagawaensis var. orobolere and identified to be psi-tectorigenin (I), ${ }^{2,3)}$ genistein (II), ${ }^{4)}$ orobol (IV), ${ }^{5)} 8$-hydroxy genistein $(\mathrm{V})^{2)}$ and a new compound. In this paper, we report on the structure of this compound, which was elucidated to be $3^{\prime}, 4^{\prime}, 5,7$-tetrahydroxy-8-methoxyisoflavone (III).

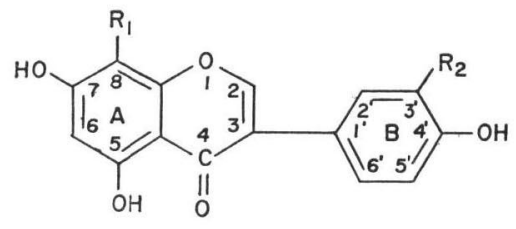

$\begin{array}{ccl}\text { Compound } & \mathrm{R}_{1} & \mathrm{R}_{2} \\ \text { I } & \mathrm{OCH}_{3} & \mathrm{H} \\ \text { II } & \mathrm{H} & \mathrm{H} \\ \text { III } & \mathrm{OCH}_{3} & \mathrm{OH} \\ \text { IV } & \mathrm{H} & \mathrm{OH} \\ \text { V } & \mathrm{OH} & \mathrm{H}\end{array}$

III has the molecular formula $\mathrm{C}_{16} \mathrm{H}_{12} \mathrm{O}_{7}$ (MW 316.26), m.p. $252^{\circ} \mathrm{C}$ (dec.). Anal. Found: $\mathrm{C}, 60.43$; H, 3.86; O, 35.39. Calcd.: C, 60.76; H. 3.82; O, 35.41. $\mathrm{M}^{+}$, m/e 316. IR $\nu_{\mathrm{KBr}}$ : $3400,1660,1530,1450$, $1380,1270,1240,1180,1115,1065,1035,995,910,865,830,780,730$ and $680 \mathrm{~cm}^{-1}$. UV $\lambda_{\max }^{\text {EtoH }}(\log \epsilon)$ : $269 \mathrm{~nm}$ (4.48) and $295 \mathrm{~nm}$ (shoulder). The isoflavone structure was suggested by the UV spectrum and the presence of a singlet proton signal at $\delta 8.08$ which is characteristic of the $\mathrm{C}_{2}$-proton of an isoflavone compound. III gave positive ferric chloride (dark blue) and GIBB's (brown) tests for a phenolic hydroxyl group. The NMR spectrum in octadeuterodioxane showed the presence of one methoxyl group ( $\delta 3.83)$, a hydrogen-bonded hydroxyl group $(\delta 12.65)$, three deutrium-exchangeable hydroxyl groups $(\delta 8.73$, $\delta 7.68$ and $\delta 7.55)$, the $\mathrm{C}_{2}$-proton $(\delta 8.08)$, one proton on ring $\mathrm{A}(\delta 6.30$, singlet) and three aromatic protons on ring $\mathrm{B}(\delta 7.15, \delta 6.87$ and $\delta 6.85)$. Acetylation of III with acetic anhydride and sulfuric acid afforded the tetraacetyl derivative, m.p. $158^{\circ} \mathrm{C}$. Treatment of III with dimethyl sulfate afforded the tetramethyl ether derivative, m.p. $164^{\circ} \mathrm{C}$.

Addition of either aluminum chloride or anhydrous sodium acetate to a solution of III caused red shifts of the main UV absorption band by 14 or $11 \mathrm{~nm}$ respectively. These properties are characteristics of hydroxyl groups located at the 5 and 7 positions. ${ }^{9)}$ A bathochromic shift was not observed by addition of $\mathrm{NaOAc} / \mathrm{H}_{3} \mathrm{BO}_{3}$ to a methanolic solution of III. This suggested that III did not contain orthodihydroxyl groups at C-6,7 or C-7,8. ${ }^{10)}$ These data indicated that two of the four hydroxyl groups were present at the 5 and 7 positions in the ring $\mathrm{A}$ of the isoflavone. The presence of the 5-hydroxyl group was also supported by its NMR spectrum ( $\delta 12.65$ described above) indicating the formation of a hydrogen bond with the carbonyl group. By oxidative degradation with alkaline hydrogen peroxide, 
the tetramethyl ether of III gave 3,4-dimethoxy benzoic acid which was identified by direct comparison of its IR spectrum with that of an authentic sample. Therefore, the other two hydroxyl groups are located at the $3^{\prime}$ and $4^{\prime}$ positions in ring $B$ of the isoflavone.

The five methoxyl peaks in the NMR spectrum of the tetramethyl ether of III in deuterochloroform appeared at $\delta 4.00,3.95,3.91,3.90$ and 3.88 , and shifted to $\delta 3.78,3.50,3.47,3.41$ and 3.26 when hexadeuterobenzene was used as the solvent. This solvent shift is consistent with a 5,7,8-oxygenation pattern in the ring $\mathrm{A}$ as reported by WiLSON et al. ${ }^{7)}$ and Sidwell et al.$^{8)}$ Nuclear OVERHAuser effects were observed between the aromatic proton $\left(\delta 6.00\right.$, benzene- $\left.\mathrm{d}_{6}\right)$ of ring $\mathrm{A}$ and the 7 position ${ }^{7)}$ methoxyl signal $(\delta 3.26)\left(+11.4 \% \mathrm{CH}\left\{\mathrm{OCH}_{3}\right\}\right)$, and, the 5 position ${ }^{7)}$ methoxyl signal $(\delta 3.47)(+11.8 \%$ $\mathrm{CH}\left\{\mathrm{OCH}_{3}\right\}$ ). These results indicated the presence of an aromatic proton at the 6 position. The presence of a methoxyl group at the 8 position of ring A was deduced from the UV shifts caused by addition of aluminum chloride and anhydrous sodium acetate. It was further confirmed by the absence of a nuclear OVERHAUSER effect between the singlet proton $(\delta 6.30)$ at the 6 position and the methoxyl group in the NMR spectrum of III.

Thus, the structure of III was deduced to be $3^{\prime}, 4^{\prime}, 5,7$-tetrahydroxy-8-methoxyisoflavone.

\section{Experimental}

UV spectra were measured by a Hitachi EPS-3T UV spectrometer, IR spectra by a Hitachi EPI-S2 Infrared spectrometer, NMR spectra by a Varian HA-100D spectrometer, mass spectra by a Hitachi RMU-6M spectrometer. The ferric chloride color reaction was achieved with $1 \%$ ferric chloride solution in water $(\mathrm{w} / \mathrm{v})$. The color by GiBB's reagent $[1 \%$ solution of 2,6 -dichloroquinonechlorimide in ethanol $(\mathrm{w} / \mathrm{v})]$ was developed with ammonia vapor after spraying.

The UV spectrum with $\mathrm{AlCl}_{3}$ was measured immediately after the addition of three drops of $10 \% \mathrm{AlCl}_{3}$ in ethanol to an ethanolic solution of III. The UV spectrum with $\mathrm{NaOAc}$ was determined immediately after the addition of excess anhydrous $\mathrm{NaOAc}$ (powder) to an ethanolic solution of III. The $\mathrm{NaOAc} / \mathrm{H}_{3} \mathrm{BO}_{3}$ spectrum was determined immediately after the addition of excess $\mathrm{NaOAc}$ and $\mathrm{H}_{3} \mathrm{BO}_{3}$ to a methanolic solution of III. III was dissolved to give a $4.5 \mu \mathrm{g} / \mathrm{ml}$ concentration in all cuvettes.

Tetraacetate of III.

To $0.5 \mathrm{ml}$ of an acetic anhydride solution of III $(20.5 \mathrm{mg})$ was added one drop of conc.sulfuric acid. The reaction mixture was allowed to stand for 1 hour at room temperature. To the mixture was added $3 \mathrm{ml}$ of water and the precipitate was collected and washed with water on a glass filter. The precipitate was crystallized from methanol, $10.8 \mathrm{mg}$, (yield $38 \%$ ), m.p. $158^{\circ} \mathrm{C}$, UV $\lambda_{\mathrm{max}}^{\mathrm{MeOH}}(\log \epsilon): 250 \mathrm{~nm}(4.72)$ and $310 \mathrm{~nm}$ (shoulder), NMR $\delta_{\text {TMS }}\left(\mathrm{CDCl}_{3}\right): 2.29$ (6H, singlet), 2.39 (3H, singlet), $2.40(3 \mathrm{H}$, singlet), 3.98 (3H, singlet), $6.83\left(1 \mathrm{H}\right.$, singlet), $7.2 \sim 7.45\left(3 \mathrm{H}, \mathrm{ABX}\right.$ system) and $7.98\left(1 \mathrm{H}\right.$, singlet), IR $\nu_{\mathrm{KBr}}: 3450$, $1770,1650,1510,1490,1415,1370,1295,1270,1200,1180,1110,1060,1030,1010,905,895,840$ and $810 \mathrm{~cm}^{-1}$.

Tetramethyl ether of III.

To $8 \mathrm{ml}$ of a refluxing acetone solution of III $(15.0 \mathrm{mg})$ and potassium carbonate $(180 \mathrm{mg})$ was added dropwise dimethyl sulfate in five portions (total $0.2 \mathrm{ml}$ ) at 10 -minute intervals. The reaction mixture was allowed to stand overnight and then evaporated under reduced pressure at $40^{\circ} \mathrm{C}$. The residue was suspended in water and filtered on a glass filter. After being washed with water, the tetramethyl ether of III was obtained as a white powder $\left(12.2 \mathrm{mg}\right.$, yield $69 \%$, m.p. $164^{\circ} \mathrm{C}$, UV $\lambda_{\max }^{\mathrm{MeOH}}(\log \epsilon): 264$ $\mathrm{nm}$ (4.56) and $290 \mathrm{~nm}$ (shoulder), NMR $\delta_{\text {TMS }}$ (benzene- $\left.\mathrm{d}_{6}\right): 3.26(3 \mathrm{H}$, singlet), $3.42(3 \mathrm{H}$, singlet), 3.47 $(3 \mathrm{H}$, singlet), $3.50(3 \mathrm{H}$, singlet), 3.78 ( $3 \mathrm{H}$, singlet), $6.00(1 \mathrm{H}$, singlet), $6.66(1 \mathrm{H}$, doublet $\mathrm{J}=8 \mathrm{~Hz})$, $7.08\left(1 \mathrm{H}\right.$, double doublet), $7.29(1 \mathrm{H}$, doublet $\mathrm{J}=2 \mathrm{~Hz})$ and $7.38\left(1 \mathrm{H}\right.$, singlet), IR $\nu_{\mathrm{KBr}}: 3450,2950$, $1660,1605,1575,1520,1470,1410,1360,1315,1270,1210,1140,1090,1070,1020,980,880$ and 820 $\mathrm{cm}^{-1}$. 
Oxidative degradation of the tetramethyl ether of III.

Hydrogen peroxide $(30 \%, w / v)$ was added dropwise with stirring in five portions (total $0.3 \mathrm{ml})$ at 10-minute intervals to a solution of the tetramethyl ether $(12.5 \mathrm{mg})$ in $5 \%$ ethanolic $(\mathrm{w} / \mathrm{v})$ potassium hydroxide at $50^{\circ} \mathrm{C}$. After one hour at $50^{\circ} \mathrm{C}$, the reaction mixture was evaporated under reduced pressure and the residue was dissolved in $20 \mathrm{ml}$ of water. The aqueous layer was washed with three $10-\mathrm{ml}$ portions of chloroform, acidified with $1 \mathrm{~N} \mathrm{HCl}$, and then extracted with chloroform and ethyl acetate (10-ml portions each). The combined organic extracts were evaporated under reduced pressure to give an acidic material $(2.8 \mathrm{mg}$, yield $46 \%$ ) which was identified as 3,4-dimethoxy benzoic acid by direct comparison of its IR spectrum with that of an authentic sample.

\section{References}

1) Umezawa, H.; H. Tobe, N. Shibamoto, F. Nakamura, K. Nakamura, M. Matsuzaki \& T. Takeuchi: Isolation of isoflavones inhibiting dopa decarboxylase from fungi and streptomyces. J. Antibiotics 28 : $947 \sim 952,1975$

2) Baker, D.; D. F. Downing, A. J. Floyd, B. Gilbert, W. D. Ollis \& R. C. Russell: Synthesis of isoflavones. V. Irigenin and tectorigenin. J. Chem. Soc. C. Organic Chemistry 1970: 1219 1223, 1970

3) FARKAS, L. \& J. VÁRADY: Über die Ringisomerisierung von Isoflavonen. I. Synthese des 5,7,8,4'Tetrahydroxy-isoflavons und des 7,4'-Dimethyl-tectorigenins. Acta Chim. Hung. 24: $225 \sim 230,1960$

4) Ganguly, A. K. \& Z. Sarre: Genistein and daidzein, metabolites of Micromonospora halophytica. Chemistry \& Industry 1970: 201, 1970

5) Charaux, C. \& J. Rabaté: Constitution chimique de l'orobol. Bull. Soc. Chim. Biol. 21: 1330 1333, 1939

6) Schwarz, J. S. P.; A. I. Cohen, W. D. Ollis, E. A. Kaczka \& L. M. Jackman: The extractive of Piscidia erythrina L. I. The constitution of ichthynone. Tetrahedron 20: 1317 1330, 1964

7) Wilson, R. G.; J. H. Bowie \& D. H. Williams: Solvent effects in NMR spectroscopy. Solvent shifts of methoxyl resonances in flavones induced by benzene; an aid to structure elucidation. Tetrahedron 24: $1407 \sim 1414,1968$

8) Sidweli, W. T. L. \& Ch. TAmm: The homo-isoflavones. II. Isolation and structure of 4'-O-methylpunctatin, autumnalin and 3,9-dihydroautumnalin. Tetrahedron Letters 1970-7: 475 478, 1970

9) Horowitz, R. M. \& L. JuRD: Spectral studies on flavonoid compounds. II. Isoflavones and flavanones. J. Org. Chem. 26: 2446 2449, 1961

10) Fukui, H.; H. Egawa, K. Koshimizu \& T. Mitsur: A new isoflavone with antifungal activity from immature fruits of Lupinus luteus. Agr. Biol. Chem. 37: 417 421, 1973 